\title{
BOUNDS FOR LINEAR FUNCTIONALS ON MONOTONE FUNCTIONS IN $L^{p}$-SPACES
}

\author{
AGNIESZKA GORONCY
}

Abstract. We consider the $L^{p}[a, b]$ space of functions which are integrable in the $p$-th power on a finite interval $[a, b]$, for $1 \leqslant p<\infty$. We establish optimal bounds on continuous linear functionals over this space, imposing the restrictions on elements of the space, which are assumed to be nondecreasing, integrable to zero, with the unit norm. We mention some applications of the bounds in the probability and statistics.

Mathematics subject classification (2010): 26D15, 46E30.

Keywords and phrases: $L^{p}$ space, linear functional, monotone function, optimal bound, Hölder inequality, Minkowski inequality, projection.

\section{REFERENCES}

[1] H. A. David And H. N. Nagaraja, Order Statistics, 3rd Ed., Wiley, Hoboken, NJ, 2003.

[2] N. Dunford AND J. Schwartz, Linear Operators, Part I, Interscience, New York, 1958.

[3] A. Goroncy And T. Rychlik, How deviant can you be? The complete solution, Math. Inequal. Appl., 9 (2006), 633-647.

[4] D. S. Mitrinović, Analytic Inequalities, Springer-Verlag, Berlin, 1970.

[5] S. Moriguti, A modification of Schwarz's inequality, with applications to distributions, Ann. Math. Statist., 24 (1953), 107-113.

[6] T. RYCHLIK, Sharp inequalities for linear combinations of elements of monotone sequences, Bull. Polish Acad. Sci. Math., 40 (1992), 247-254.

[7] T. RYCHLiK, Projecting Statistical Functionals, Lecture Notes in Statistics, Vol. 160, Springer-Verlag, New York, 2001.

[8] T. RYCHLIK, Optimal bounds for linear functionals on monotone functions, Math. Inequal. Appl., 10 (2007), 299-310. Correction: Math. Inequal. Appl., 10 (2007), 711. 